\title{
A New Improved Trans Z Source Inverter based Three Phase UPS
}

\author{
A. Radhika', P. Maruthupandi ${ }^{2}$, J. Karthika' and R. Geethamani ${ }^{1}$ \\ 'Department of Electrical and Electronics Engineering, Sri Krishna College of Engineering and Technology, Coim- \\ batore-641 008,Tamil Nadu, India; radhika@skcet.ac.in, karthika@skcet.ac.in, geethamani@skcet.ac.in \\ ${ }^{2}$ Department of Electrical and Electronics Engineering, Government College of Technology, \\ Coimbatore - 641 013, Tamil Nadu, India; pandi@gct.ac.in
}

\begin{abstract}
Objective: In applications like Wind Energy Conversion System, electric cell power conversion and Grid-connected PV generation, a small DC source voltage should be boosted to induce fascinating AC output voltage. Methods/Statistical Analysis: Z Structured Impedance Source Inverter (ZSI) is well-liked for its buck to boost operations. The high voltage gain will be obtained from the normal Z Structured Impedance Source Inverter at low modulation index state. On the other side, a little modulation index state produces high voltage stress at the inverter side switches. To defeat this problem, a Trans Z Structured Impedance Source Inverter (TZSI) is developed. In TZSI, transformer winding turns demand is high and the windings get burnt because of high instant current throughout shoot through length. Findings: A new topology of Trans Z Structured Impedance Source Inverter is introduced in this paper to boost the voltage gain fair enough. In this new topology the winding turn's usage is smaller amount and consequently inverter gain is lift up by lower the modulation index. To validate the ideas planned in theories, experimental results were taken and bestowed in this paper. Application: This inverter is utilized for three faze Uninterruptable Power Supply. The proposed inverter is designed and simulated in MATLAB/Simulink podium for $3 \mathrm{KVA}$ load capacity and it will sustain the specified output voltage with the substantial drop in voltage at battery bank side.
\end{abstract}

Keywords: PWM Inverter, Shoot Through Period, Trans Z Source Inverter (TZSI), Uninterruptable Power Supply (UPS), Z Source Inverter (ZSI)

\section{Introduction}

Uninterruptible Supply scheme is used to offer uninterrupted, consistent and prime quality power to critical loads. It offers protection against irregular power-line voltage or power outage to critical loads. Three different UPS are there traditionally in three wire system. The primary type stepped up transformer needs enhanced inverter side output voltage ${ }^{1}$, as in Figure 1(a). At this time the current in inverter is much higher than the current at load side. Owing to this, current stress raise happens on the switches in inverter and conjointly increases transformer weight, size and volume. The second kind requires DC/ DC boost converter, inverter as in Figure 1(b). During this type, the extra boost converter results in high prize, difficult boost management and low efficient output. The inverter with dead time requires protection for short circuit of inverter in the same leg. Also dead time distorts the output voltage wave shape. The third sort UPS, the necessity of booster circuit is eliminated and it provides single stage power translation during $\mathrm{ZSI}^{2-6}$ as like Figure $1(\mathrm{c})$. The voltage plane of ZSI isn't ample with low modulation index $(\mathrm{M})$ condition from $\frac{7-10}{}$. In addition ZSI leads high voltage stress in switching mechanism $\frac{11-13}{}$.

To overcome listed troubles in the TZSI is introduced. In TZSI transformer winding turns demand is high.

This study presents a unique topology of Trans Z Structured Impedance Source Inverter so as to produce

*Author for correspondence 
improved performance in TZSI. This improved TZSI is implemented in UPS system, as shown in Figure 1 (d). This new suggested UPS offers the subsequent deserves than the traditional UPS:

- One step power conversion by mingling DC/DC converter with the inverter operation.

- Elimination of dead time interval within the PWM signal results reduction of AC output-voltage wave shape distortion.

- The output voltage level inverter is high enough throughout low modulation index condition by means of voltage stress reduction across the switching elements.

- The transformer winding turns demand is smaller amount and it needs less shoot through duration

- Quick transient response and sensible steady state performance is achieved by adopting twin-loop control.

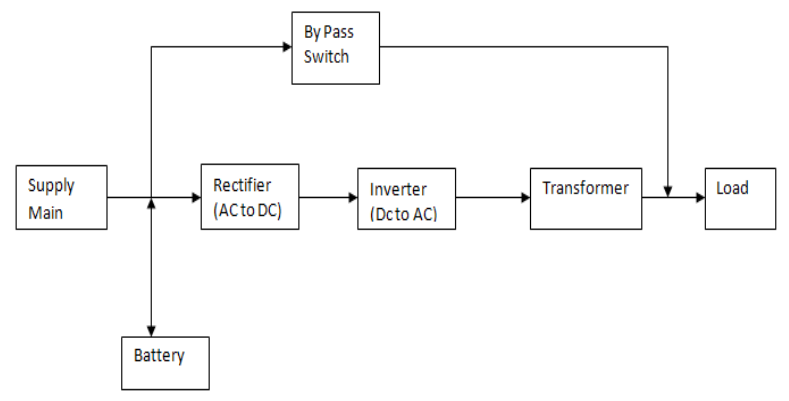

(a)

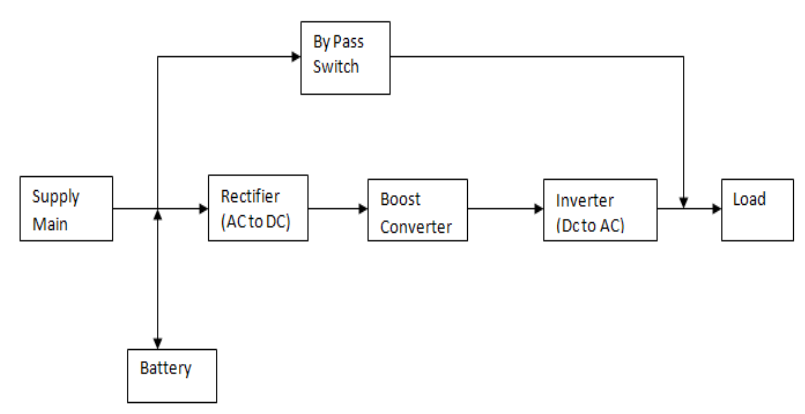

(b)

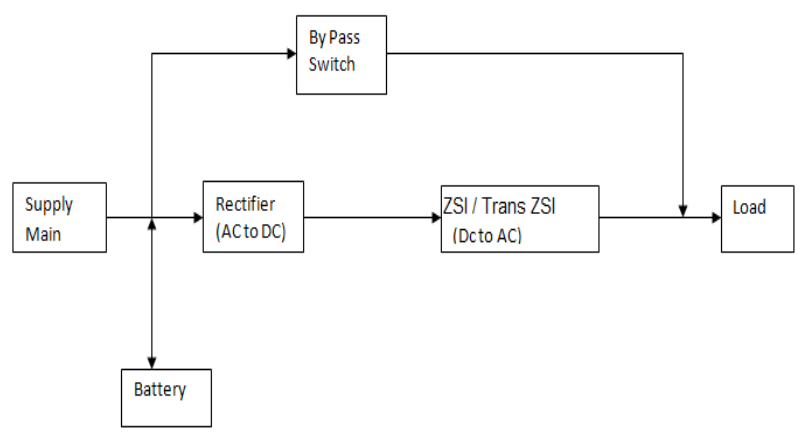

(c)

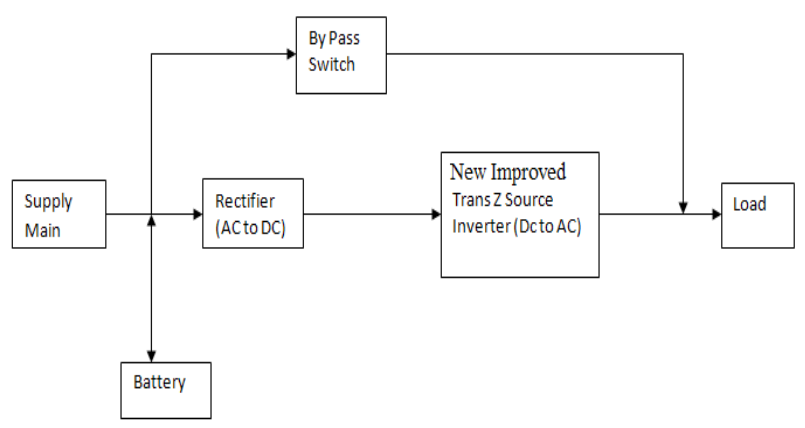

(d)

Figure 1. Topologies of UPS.

(a) Inverter + Transformer. (b) DC/DC Booster + inverter.

(c) Z/Trans ZSI. (d) A New Improved Trans ZSI.

\section{System Arrangement and Description}

Figure 1(d) shows a brand new topology of the UPS through a proposed inverter. During regular operation, the battery bank and inverters are powered by the rectifier unit. In case of power failure, the battery bank energises the inverter as like Figure 2.

It consists of a DC supply (Rectifier, battery V DC, Capacitor $\mathrm{C} 4$ and diode D), Novel impedance network (W1, W2, C1, C2 and C3), PWM inverter switch (S1S6), Inductive Filter Ls and Capacitive filter Cs. The gate pulses to the inverter are given as Z Structured Impedance Source Inverter triggering. The Novel impedance network makes the projected UPS to produce the desired AC output voltage, in spite of the battery powered DC voltage. While improved TZSI in T1 time interval (non shootthrough state), on condition of diode $\mathrm{D}$, starts to charging of capacitors $\mathrm{C} 1$ and $\mathrm{C} 2$ in one direction while $\mathrm{C} 3$ in conflicting direction.

The improved TZSI equivalent circuit on non shootthrough interval (T0) is viewed in Figure 3.

The consequent voltage expression is written as:

$$
\begin{aligned}
& V c 1+V c 2=V i n \\
& V w 1+V c 1=V d c
\end{aligned}
$$

The C2 capacitor voltage is remains same as of winding W2 voltage. Once Improved TZSI is Functioning on shoot-through state (T0 time Interval), D the diode is in reverse bias condition. $\mathrm{C} 1$ and $\mathrm{C} 2$ Capacitors discharge their stored energy to the transformer. Improved TZSI on shoot-through time interval is bestowed in Figure 4. The respective voltage expressions are written as: 


$$
\begin{aligned}
& V w 2=V c 2=-V c 1 \\
& V w 2=V w 1+V c 3
\end{aligned}
$$

$\mathrm{VC} 1$ Average value $=0$

$$
\begin{aligned}
& (V d c-V w 1) T 1-V w 2 T o=0 \\
& V w 2=\frac{V d c T 1}{n T 1+T 0}
\end{aligned}
$$

VC2 Average value $=0$

$$
\begin{aligned}
& (V c 1-V i n) T 1+V c 1 T 0=0 \\
& V c 1=\frac{V i n T 1}{T} \\
& V i n=\frac{V d c T 1}{(n T 1+T 0) d} \\
& V i n=B V d c \\
& B=\frac{T 1}{(n T 1+T 0) d} \geq 1
\end{aligned}
$$

Vin Peak DC link voltage, B boost factor is acquired at shoot through interval. Vac The peak phase voltage is expressed as

$$
\begin{aligned}
& V a c=M B \frac{V d c}{2} \\
& V a c=M \frac{T 1 V d c}{(n T 1+T 0) 2 d}
\end{aligned}
$$

Where $M$ is modulation index?

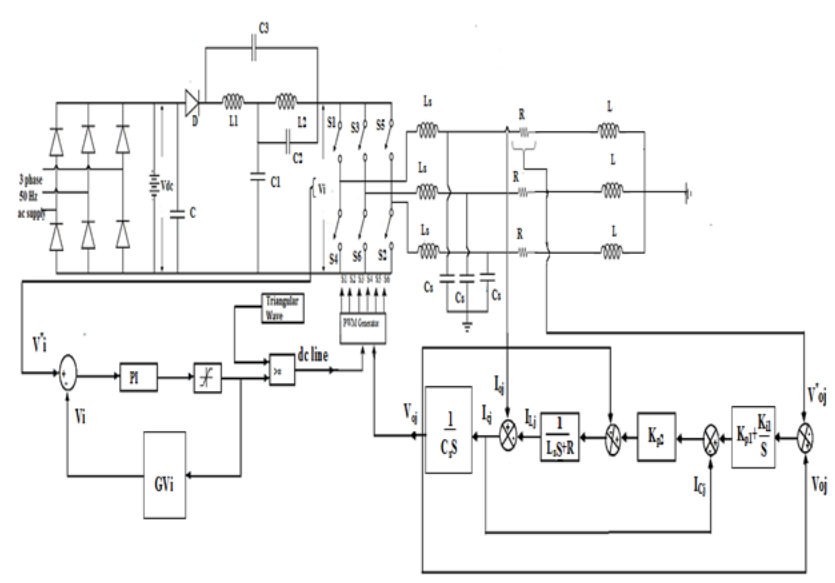

Figure 2. Proposed UPS with new improved TZSI.

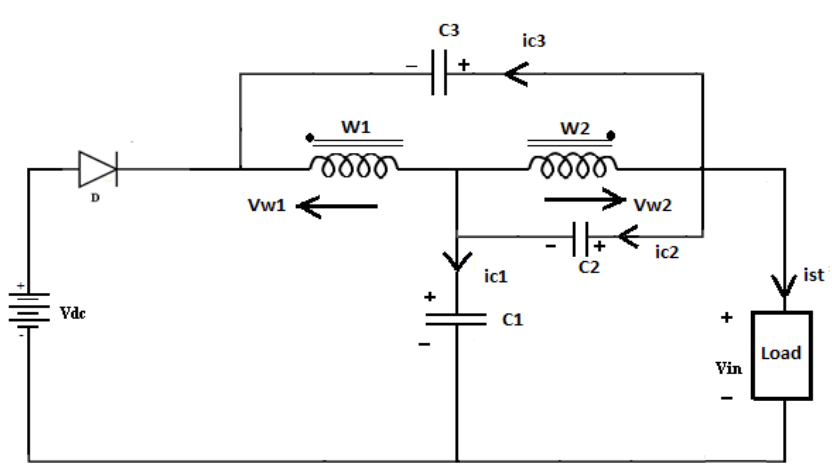

Figure 3. New improved ZSI in non shoot-through interval.

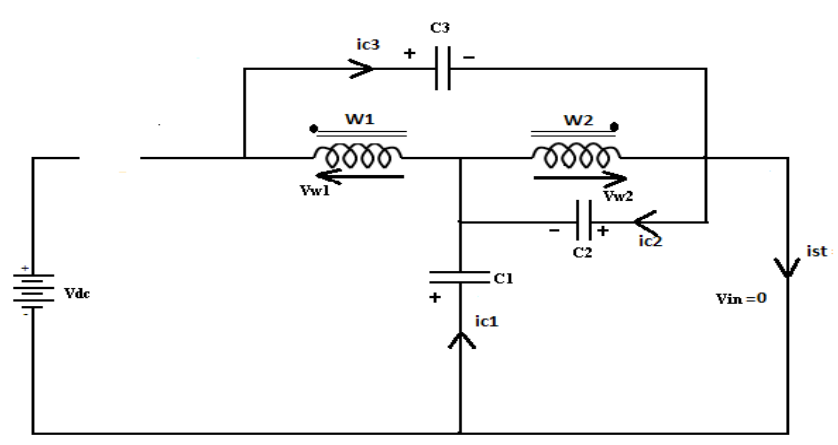

Figure 4. New improved ZSI in shoot-through interval.

\section{Proposed UPS with Improved RZSI Control}

Figure 2 presents proposed UPS twin loop control with improved TZSI. The appropriate choice of $\mathrm{d}$ and $\mathrm{M}$ produces the necessary output voltage despite of battery voltage. The range of $\mathrm{T} 0$ period is decided by duty ratio. This involves control of DC link voltage level and it is revealed in Figure 5. Reference voltage $V *_{i}$ compared with DC link voltage $\mathrm{V}_{\mathrm{i}}$.

The error signal sent to the PI Controller to optimize the output voltage and it is limited to 0.99 . Therefore the saturation limiter connected to the controller circuit and it limits the error signal to maximum of 0.99 . Thus the simple boost controller DC line obtains the constant value from this limiter. The DC constant value is match up with the triangular wave to estimate shoot though interval. The evaluation of shoot through interval (T0) is shown in Figure 6. 


$$
\left[\begin{array}{l}
\dot{\mathrm{I}}_{\mathrm{L} 1} \\
\dot{\mathrm{I}}_{\mathrm{L} 2} \\
\dot{\mathrm{V}}_{\mathrm{C} 1} \\
\dot{\mathrm{V}}_{\mathrm{C} 2} \\
\dot{\mathrm{V}}_{\mathrm{C} 3}
\end{array}\right]=\left[\begin{array}{ccccc}
0 & 0 & -\frac{1}{\mathrm{CL}} & 0 & 0 \\
0 & 0 & 0 & \frac{1}{\mathrm{CL}} & 0 \\
\frac{1}{\mathrm{CL}} & -\frac{1}{\mathrm{CL}} & 0 & 0 & 0 \\
\frac{1}{\mathrm{CL}} & \frac{1}{\mathrm{CL}} & 0 & 0 & 0 \\
\frac{1}{\mathrm{CL}} & 0 & 0 & 0 & 0
\end{array}\right] *\left[\begin{array}{c}
\mathrm{I}_{\mathrm{L} 1} \\
\mathrm{I}_{\mathrm{L} 2} \\
\mathrm{~V}_{\mathrm{C} 1} \\
\mathrm{~V}_{\mathrm{C} 2} \\
\mathrm{~V}_{\mathrm{C} 3}
\end{array}\right]+\left[\begin{array}{ccc}
0 & 0 & 1 \\
0 & 0 & 0 \\
0 & 0 & 0 \\
-1 & -\mathrm{R} & 0 \\
-1 & 0 & 0
\end{array}\right] *\left[\begin{array}{c}
\mathrm{I}_{\mathrm{dc}} \\
\mathrm{I}_{0} \\
\mathrm{~V}_{\mathrm{dc}}
\end{array}\right]
$$

In this Figure 6 the triangular carrier wave height is represented as HT and DC line voltage height is represented as HP. W and T0 are the Width of triangular carrier wave and shoot through rate is represented as $\mathrm{W}$ and $\mathrm{T} 0$.

The calculation of shoot through interval can be articulated as:

$$
T 0=\frac{H T-H P}{H T} * W
$$

The Control methodology of simple boost is revealed in Figure 7. The evaluation of shoot through interval and non shoot through interval is feasible with this flow diagram. The firing pulse for devices is often programmed victimization the Figure 7 . The modulation index control utilizes twin loop control as expressed in Figure 8. The inner load current $\left(i_{0 j}\right)$ is match up to reference current $\left(\mathrm{I}_{\mathrm{Lj}}\right)$. The result is match up with capacitor current $\left(\mathrm{I}_{\mathrm{Cj}}\right)$ and it's given to the proportional gain controller $\left(\mathrm{K}_{\mathrm{p})}\right.$. Reference output voltage $\mathrm{V}_{\mathrm{oj}}$ estimation involves the $\left(\mathrm{I}_{\mathrm{Lj}}\right)$ and $\left(\mathrm{I}_{\mathrm{Cj}}\right)$ prediction. The reference output voltage $\left(\mathrm{V}_{\mathrm{oj}}\right)$ given to feedback loop and conjointly given to the gate circuit wherever the proportional modulating sine wave voltage calculable.

By referring Figure 4 the Laplace Transform equations for T0 interval is expressed below:

$$
\begin{aligned}
& -L_{1} s I_{L 1}(s)=\frac{2}{C_{1} s} I_{C 1}(s) \\
& L_{2} s I_{L 2}(s)=\frac{1}{C_{2} s} I_{C 2}(s)=-\frac{1}{C_{1} s} I_{C 1}(s) \\
& \frac{1}{L_{1} s} I_{L 1}(s)+\frac{1}{L_{2} s} I 2(s)=C_{2} s I_{C 2}(s) \\
& C_{3} s I_{C 3}(s)=\frac{1}{L_{1} s} I_{L 1}(s)
\end{aligned}
$$

By referring Figure 3 the Laplace Transform equations for $\mathrm{T} 1$ is written below:

$$
\begin{aligned}
& L_{1} s I_{L 1}(s)+\frac{1}{C_{1} s} I_{C 1}(s)=V_{d c} \\
& L_{2} s I_{L 2}(s)=\frac{1}{C_{2} s} I_{C 2}(s) \\
& C_{1} s I_{C 1}(s)=\frac{1}{L_{1} s} I_{L 1}(s)-\frac{1}{L_{2} s} I_{L 2}(s) \\
& C_{2} s I_{C 2}(s)=\frac{1}{L_{2} s} I_{L 2}(s)+\frac{1}{L_{1} s} I_{L 1}(s)-I_{d c}-I_{0} \\
& C_{3} s I_{C 3}(s)=\frac{1}{L_{1} s} I_{L 1}(s)-I_{d c}
\end{aligned}
$$

To simplify the analysis assume $\mathrm{C} 1=\mathrm{C} 2=\mathrm{C} 3=\mathrm{C}$ and $\mathrm{L} 1=\mathrm{L} 2=\mathrm{L}$. The dynamic Equation for the T1 interval is written as:

$$
\begin{gathered}
{\left[\begin{array}{l}
\dot{I}_{L 1} \\
\dot{I}_{L 2} \\
\dot{V}_{C 1} \\
\dot{V}_{C 2} \\
\dot{V}_{C 3}
\end{array}\right]=\left[\begin{array}{ccccc}
0 & 0 & -\frac{2}{C L} & 0 & 0 \\
0 & 0 & 0 & \frac{1}{C L} & 0 \\
0 & 0 & 0 & 0 & 0 \\
\frac{1}{C L} & \frac{1}{C L} & 0 & 0 & 0 \\
\frac{1}{C L} & 0 & 0 & 0 & 0
\end{array}\right] *\left[\begin{array}{l}
I_{L 1} \\
I_{L 2} \\
V_{C 1} \\
V_{C 2} \\
V_{C 3}
\end{array}\right]} \\
\dot{X}=A_{s t} X+B_{s t} U
\end{gathered}
$$

The dynamic Equation for T0 interval is written as:

$$
\dot{X}=A_{\text {Non }} X+B_{\text {Non }} U
$$

The small signal perturbations $\hat{V}_{d c}(t)$ and $\hat{d}(t)$ are given as input level voltage and duty ratio to the state variable in order to derive the small signal model. The State Space Average Method formulated as ${ }^{14}$ :

$$
\begin{aligned}
& s C_{1} \hat{V_{C 1}}(s)=d R I_{0}(s)+R I_{0} d(s) \\
& \ddot{X}=\left(d A_{s t}+(1-d) A_{N o n}\right) \dot{X}+\left(d . B_{s t}+(1-d) B_{N o n}\right) \dot{U} \\
& \left.\quad+\left(\left(A_{s t}-A_{N o n}\right) X+\left(B_{s t}-B_{N o n}\right) U\right)\right) \hat{d}(t)
\end{aligned}
$$

Subsequent application of Laplace transform for the above Equation becomes: 


$$
\begin{aligned}
s L_{1} \hat{I_{L 1}}(s)= & \left(-\frac{(1-d}{C L}\right) V_{C 1}(s)+(1-d) I_{d c}(s) \\
& -\frac{1}{C L} V_{C 1}(s)-V_{d c} d(s) \\
s L_{2} \hat{I_{L 2}}(s)= & \frac{1}{C L} V_{C 2}(s) \\
s C_{2} \hat{V_{C 2}}(s)= & \frac{2}{L C}(1-d) V_{C 2}(s) \\
& -\left(\frac{R}{L}\right) d I_{0}(s)+\left(i_{d c}+i_{0}\right) d(s) \\
s C_{3} \hat{V_{C 3}}(s)= & \frac{1}{L C} V_{C 3}(s)-(1-d) I_{d c}(s)+I_{d c} d(s)
\end{aligned}
$$

The response of each state variable expressed as a linear combination of perturbation variables by solving the above Equations the DC side voltage gain $G V_{i}$ as follows:

$$
G V_{i}=\frac{L s^{2} I_{L 1}+\left((1-d)\left(V_{C 1}+V_{C 2}\right)-(1-d) i_{d c}\right) s-V_{d c} R}{L C s^{3}-(1-d) s^{2}-\frac{1}{L C} s+\left(1-\frac{R}{C}\right)}
$$

For the AC-side control management, the voltage regulation explored in traditional control method for the individual system. In order to get a good control system, AC side dynamics should be designed more quickly than the DC side to prevent oscillation. The control parameter change in DC side control will limit the AC side, as the shoot through interval is limited within the zero state. The controller generally will achieve good performance with higher end of input voltage.

The AC side controller consists of inner and outer control loops. Stabilized output and quicker response for a current disturbance is achieved via proportional controller that is employed in the midst of inner loop current. PI compensator, the glorious control loop that produces the stabilized variations and quick reference tracking. The Mason's gain rule applied to estimate the system transfer function as follows:

$$
\begin{aligned}
G_{I^{*} c j}^{I c j} & (s)=\frac{I c j(s)}{I^{*} c j}=\frac{K_{p 2} C_{s} s}{L_{s} C_{s} s^{2}+\left(R+K_{p 2}\right) C_{s} s+1} \\
G_{I o j}^{I c j}(s) & =\frac{I c j(s)}{I o j(s)}=\frac{L_{s} C_{s} s^{2}+R s}{L_{s} C_{s} s^{2}+\left(R+K_{p 2}\right) C_{s} s+1} \\
G_{V^{*} o j}^{V o j}(s) & =\frac{V o j(s)}{V^{*} o j(s)} \\
= & \frac{\left(K_{p 1}+K_{i 1}\right) K_{p 2}}{L_{s} C_{s} s^{3}+\left(R+K_{p 2}\right) C_{s} s^{2}+\left(1+K_{p 2} K_{p 1}\right) s+K_{i 1} K_{p 2}}
\end{aligned}
$$

$$
\begin{aligned}
G_{I o j}^{V o j}(s) & =\frac{\operatorname{Voj}(s)}{I o j(s)} \\
& =\frac{L_{s} s^{2}+R s}{L_{s} C_{s} s^{3}+\left(R+K_{p 2}\right) C_{s} s^{2}+\left(1+K_{p 2} K_{p 1}\right) s+K_{i 1} K_{p 2}}
\end{aligned}
$$

Where $G_{I^{*} c j}^{I c j}(s)$ and $G_{I o j}^{I c j}(s)$ are control input-to-output and disturbance signal-to-output side inner loop transfer function. $G_{V^{*}{ }^{\circ j}}^{V_{0 j}}(s)$ and $G_{I o j}^{V o j}(s)$ are control input-to-output, disturbance signal-to-output of outer voltage loop transfer function, respectively: $K_{p 2}, K_{p 1}, K_{i 1}$ are propor-

tional gain 2,1 and integral gain parameters respectively. Further it is given to the simple boost control strategy reference voltage control circuit to fix the modulation index value.

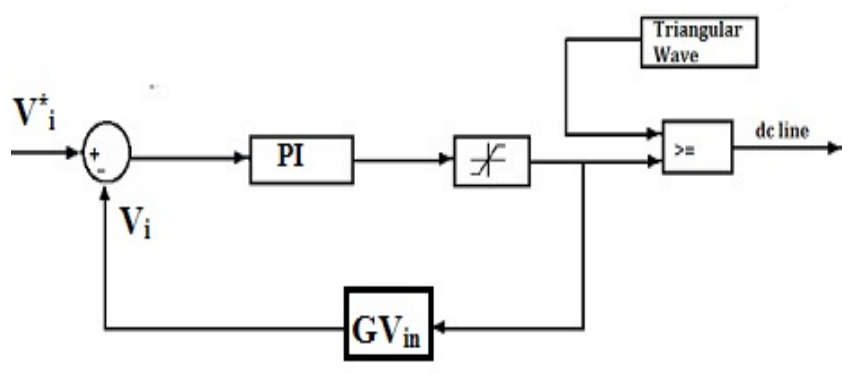

Figure 5. Block diagram of DC link control.

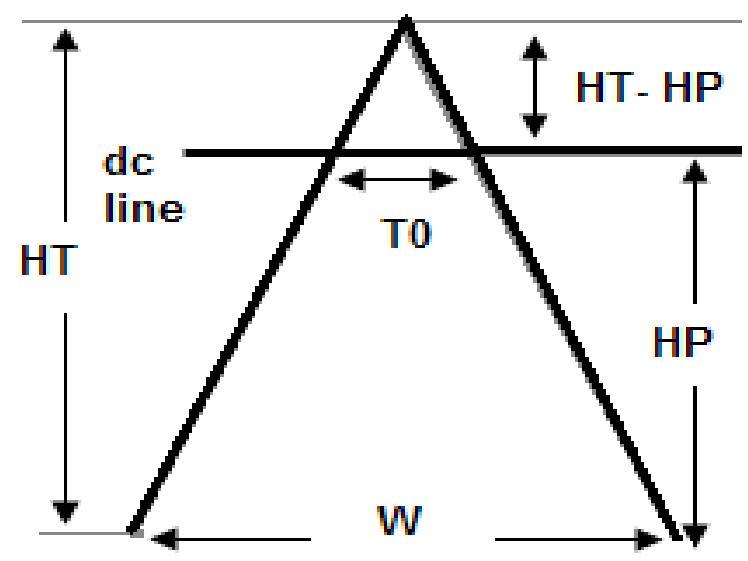

Figure 6. Evaluation of shoot through interval 


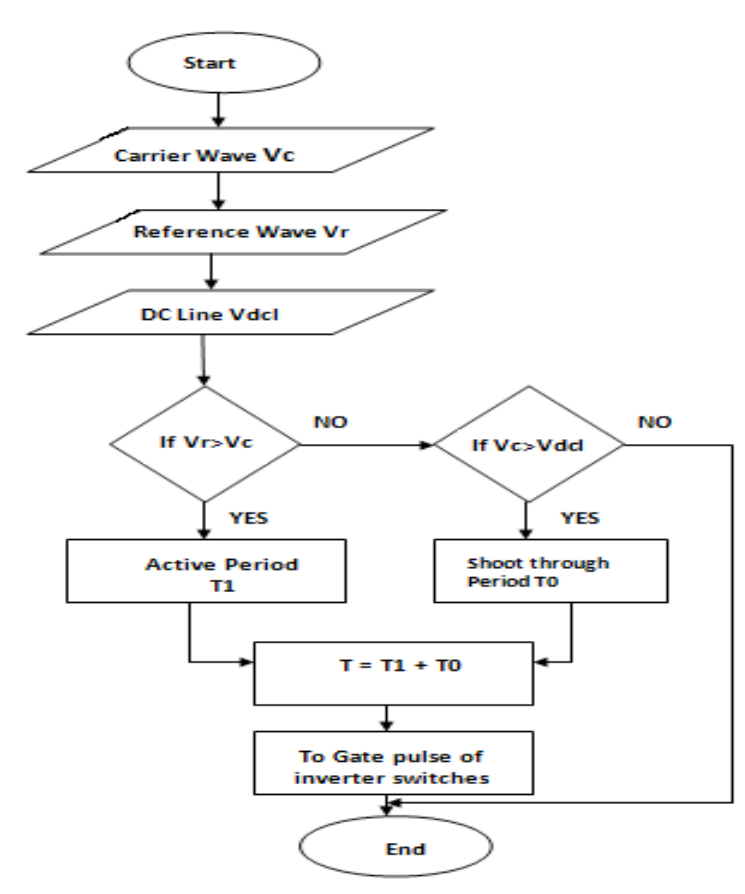

Figure 7. Flow chart for SBC method.

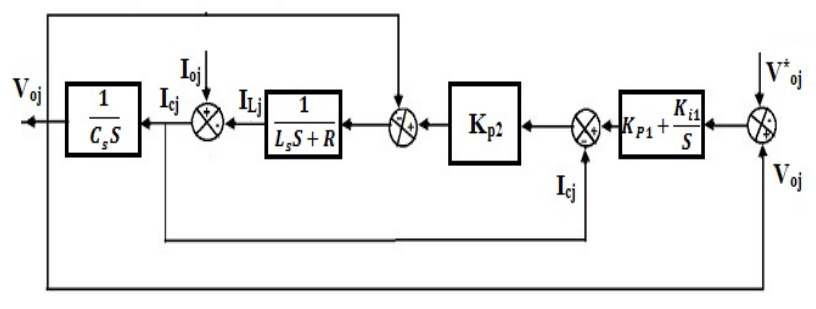

Figure 8. Block diagram of AC side control.

\section{Simulation Results and Discur- sions}

The suggested UPS is compared with traditional Z Structured Impedance Source Inverter based UPS and with Trans Z Structured Impedance Source Inverter (TZSI) based UPS. MATLAB/Simulink plat form kind is effectively utilized to replicate the system. The circuit parameter for simulation is exposed in Table 1.

The simulation is done at the switching frequency rate of $10 \mathrm{KHz}$, switching period of time Ts is $5 \times 10^{-5} \mathrm{sec}$ and T1 interval is $0.08 \times 10^{-4} \mathrm{sec}$. M, T0/T1 is set to 0.84 and 0.16 . The system intention is to generate a three phase $\mathrm{AC}$ output voltage of $415 \mathrm{~V}$ from DC voltage supply of $154.5 \mathrm{~V}$. From the above analysis the subsequent theoretical calculations are done.

$$
\begin{gathered}
\operatorname{Vin}=\frac{154.5 * 4.2 * 10^{-5}}{\left(1.5 * 4.2 * 10^{-5}+0.8 * 10^{-5}\right) 0.16}=571 \mathrm{~V} \\
\operatorname{Vac}=0.84 * \frac{4.2 * 10^{-5} * 154.5}{\left(1.5 * 4.2 * 10^{-5}+0.8 * 10^{-5}\right) 2 * 0.16}=415 \mathrm{~V}
\end{gathered}
$$

With the Equations (33) and (34) we are able to perceive that any modification in supply voltage will built variant in DC link side voltage and alteration with boost factor able to maintain AC output side voltage constant. DC link set to $571 \mathrm{~V}$ and AC line voltage set to $415 \mathrm{~V}$. The assessment between reference and actual value produces the error signal. These error signals initiate the closed loop system operation and it's given to PI controller.

PI controller transfer function is:

$$
G(S)=K_{p}+\frac{K_{i}}{s}
$$

The Proportional and Integral gain $\left(K_{p}\right.$ and $\left.K_{i}\right)$ ranges are evaluated by using Zieglers-Nichols scheme. This technique is incorporated in step response system. This system nature is normalized by two different parameters, time constant (Tp) and delay time (Lp). These parameters are calculated by sketching a tangent at the point of intersection in the step response and intersections with time axis. Thus the steady state value noted is shown in Figure 9. In the same way the error signal generated in output side voltage is processed through PI controller.

Step function to the system applied to predict the output response and $\mathrm{L}_{\mathrm{p}}$ and $\mathrm{T}_{\mathrm{p}}$ has been calculated. The calculated $\mathrm{L}_{\mathrm{p}}=1$ and $\mathrm{T}_{\mathrm{p}}=0.004$, for this the $K_{p}$ and $K_{i}$ are

0.3 and 0.1 respectively. Bode plot has been drawn to examine stable condition and it is revealed in Figure 10. Here gain margin posses positive value and the phase margin shows infinite value. Thus the system is a stable system. In conventional UPS $20 \%$ of variation in battery voltage makes wave shape distortion in inverter output voltage. The suggested UPS showing glorious voltage regulation even with $50 \%$ voltage droop in battery bank voltage. At $100 \%$ battery bank voltage (i.e. $154.5 \mathrm{~V}$ ) the UPS produces inverter side output AC voltage of $415 \mathrm{~V}$ and it is exposed in Figure 11. In 50\% of battery voltage $(78 \mathrm{~V})$, the AC side output voltage wave shape is not distorted because of Improved TZSI action and it's shown in Figure 12. Total Harmonic Distortion of UPS voltage is revealed in Figure 13. The UPS voltage THD is restricted to $0.60 \%$. Figure 12 showing some second order harmon- 
ics, this will be eliminated by selecting higher rating of capacitive filter.

The proposed UPS competency level with the conventional UPS has been calculated for different KVA ratings. It is plotted in Figure 14. It is noted that the suggested UPS has exhibited $10 \%$ greater efficiency than that of conventional UPS.

Table 1. Simulation circuit parameters for proposed UPS

\begin{tabular}{|l|l|}
\hline System Parameters & Values \\
\hline $\mathrm{V}_{\mathrm{LAC}}$-Three phase AC line voltage & $114.4 \mathrm{~V}$ \\
\hline fs - Switching frequency & $10 \mathrm{KHz}$ \\
\hline $\mathrm{T}$ - Total Switching period & $5 \times 10^{-5}$ \\
\hline T1-Active Period & $4.2 \times 10^{-5}$ \\
\hline T0-Shoot Through Period & $0.8 \times 10^{-5}$ \\
\hline C1, C2 and C3- Capacitors & $33 \mu \mathrm{F}$ \\
\hline N1- Inductor1 Winding & 108 turns \\
\hline N2- Inductor2 Winding & 72 turns \\
\hline K- coupling coefficient & 0.998 \\
\hline
\end{tabular}

\begin{tabular}{|l|l|}
\hline $\mathrm{K}_{\mathrm{p},} \mathrm{K}_{\mathrm{p} 1 \text { and }} \mathrm{K}_{\mathrm{p} 2}$ - Proportional gain & $0.05,0.03$ and 0.03 \\
\hline Integral gain & 0.1 \\
\hline Star connected R load & $3 \mathrm{KW}$ \\
\hline M- Modulation index & 0.84 \\
\hline $\mathrm{d}$ (Boost mode) - duty ratio & 0.16 \\
\hline n- Turns Ratio & 1.5 \\
\hline f- Fundamental AC frequency & $50 \mathrm{~Hz}$ \\
\hline
\end{tabular}

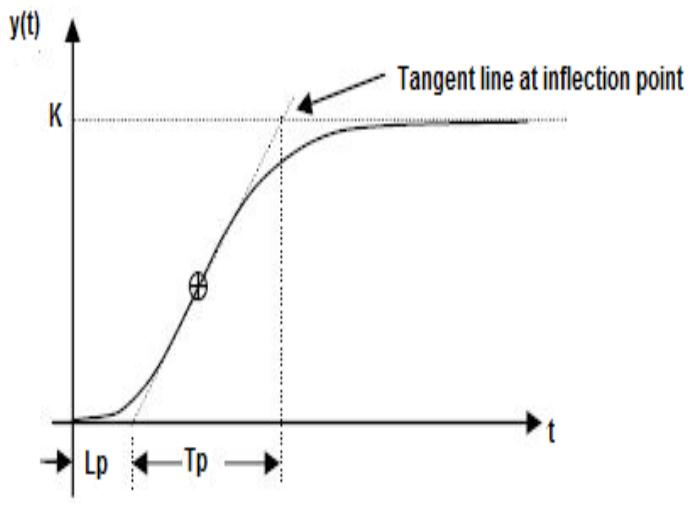

Figure 9. Zieglers-Nichols method.

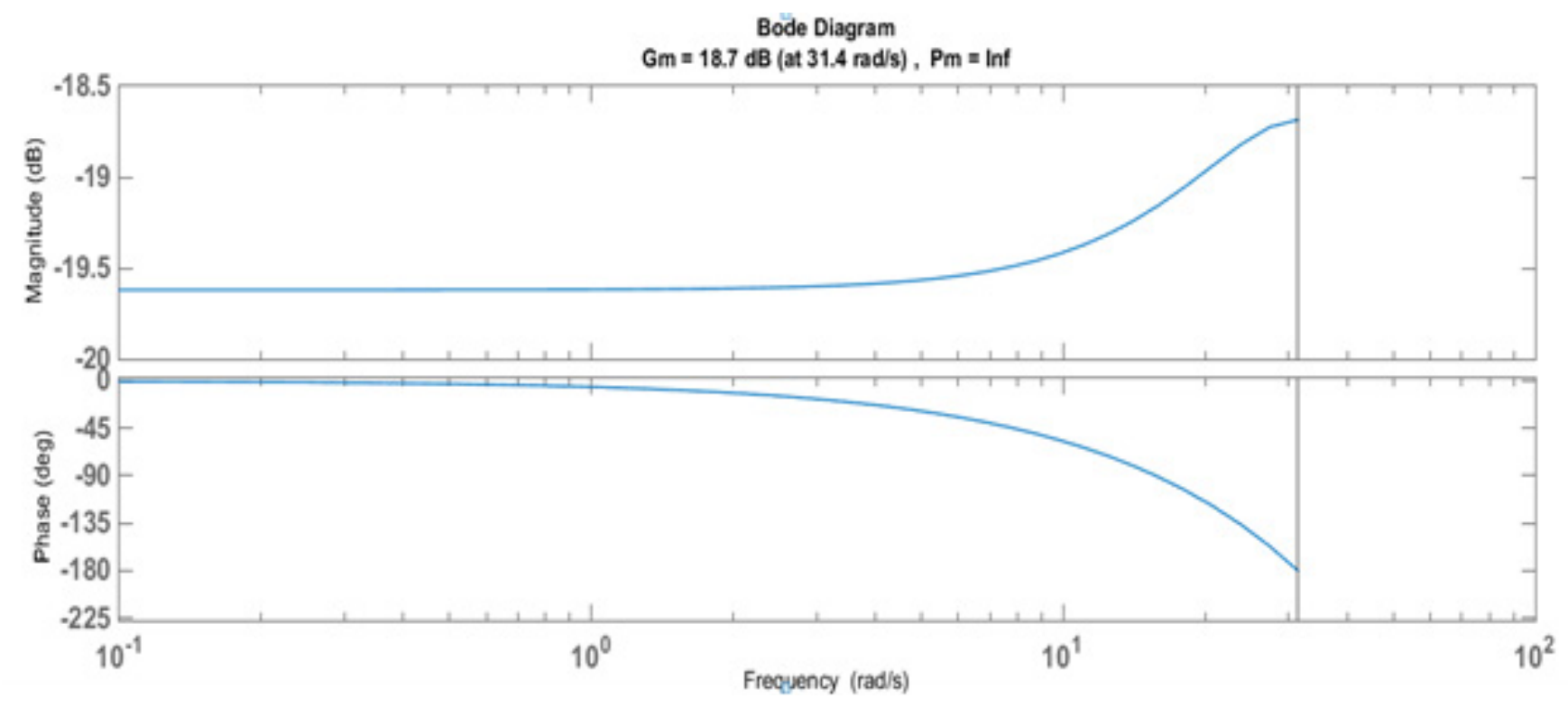

Figure 10. Bode plot for stability analysis. 

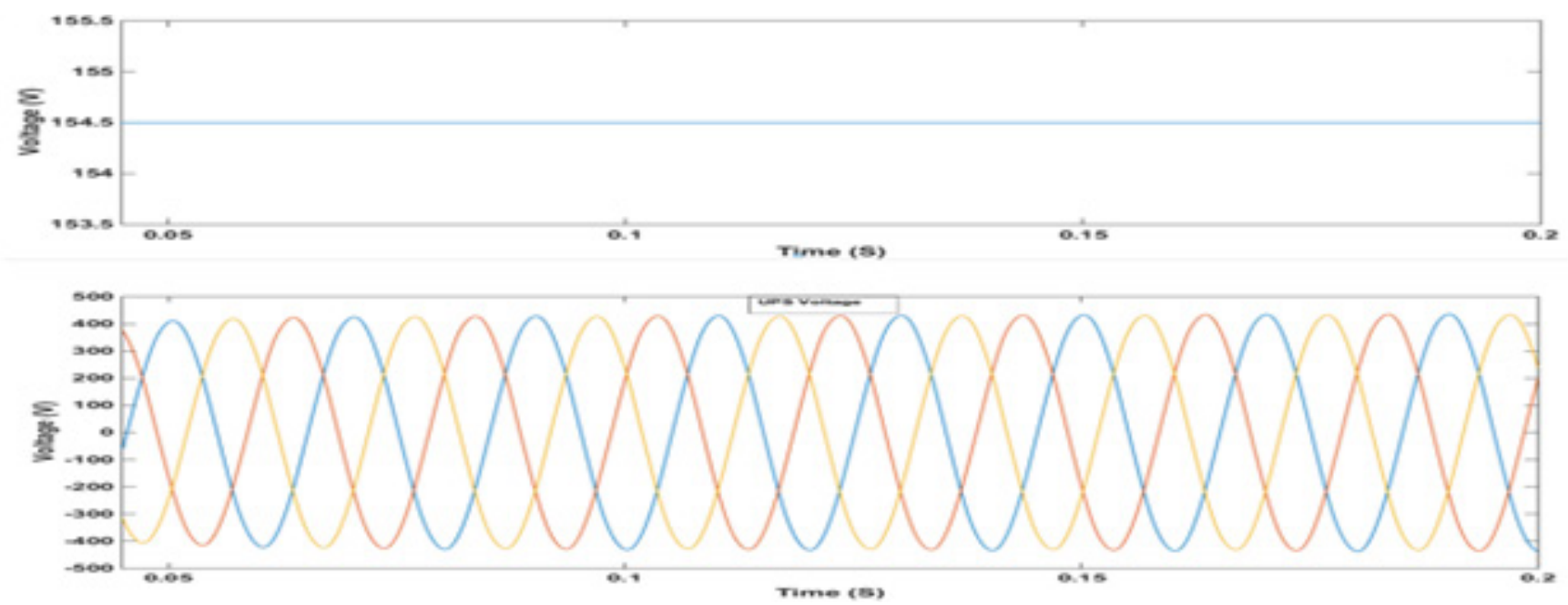

Figure 11. 100\% battery voltage vs. AC response.
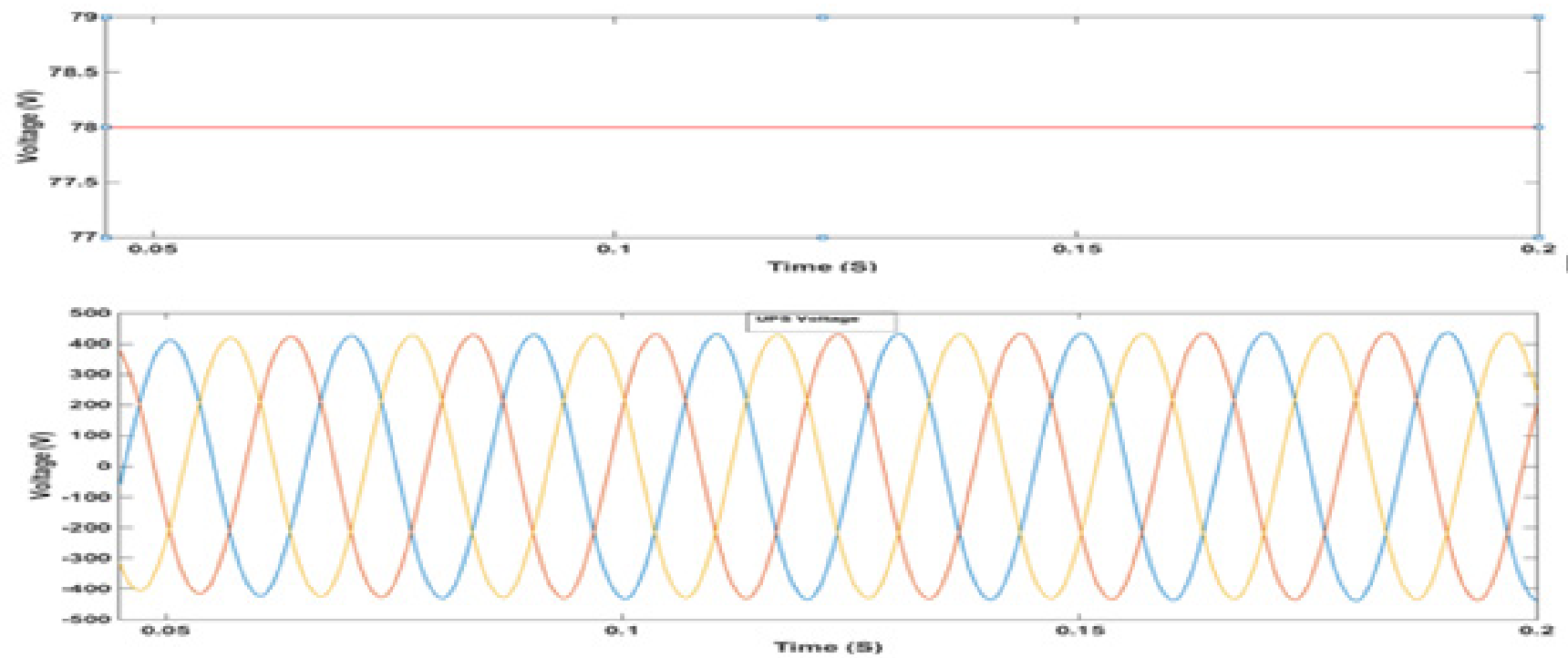

Figure 12. $50 \%$ battery voltage drop vs. AC response.

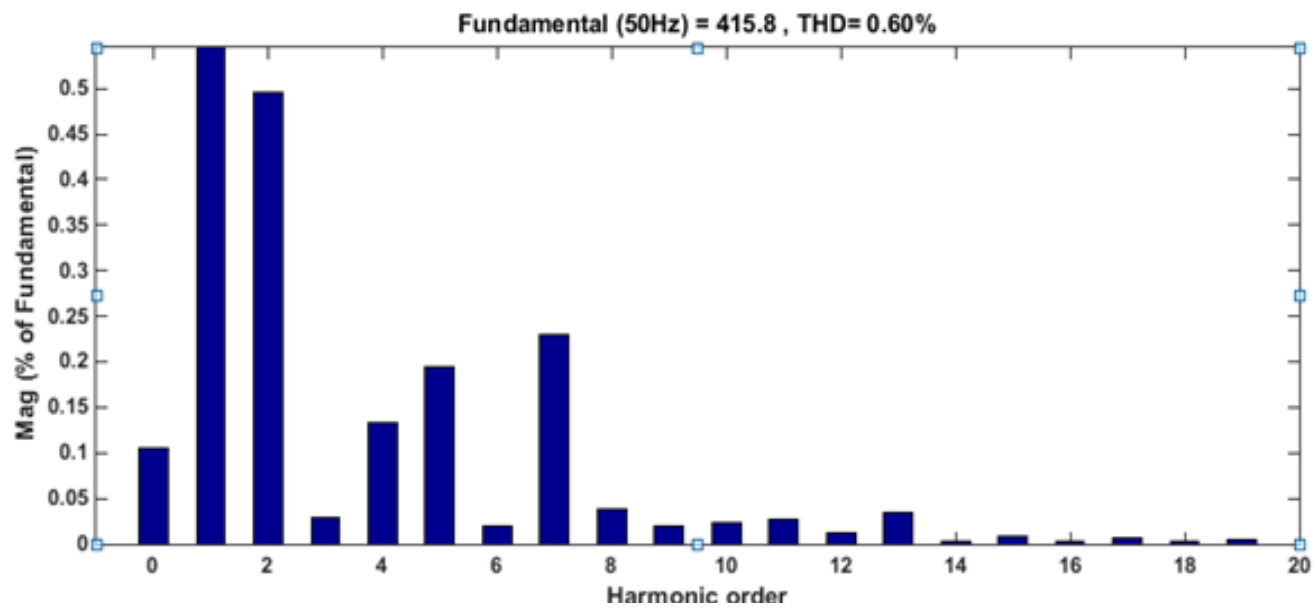

Figure 13. UPS output voltage FFT analysis. 


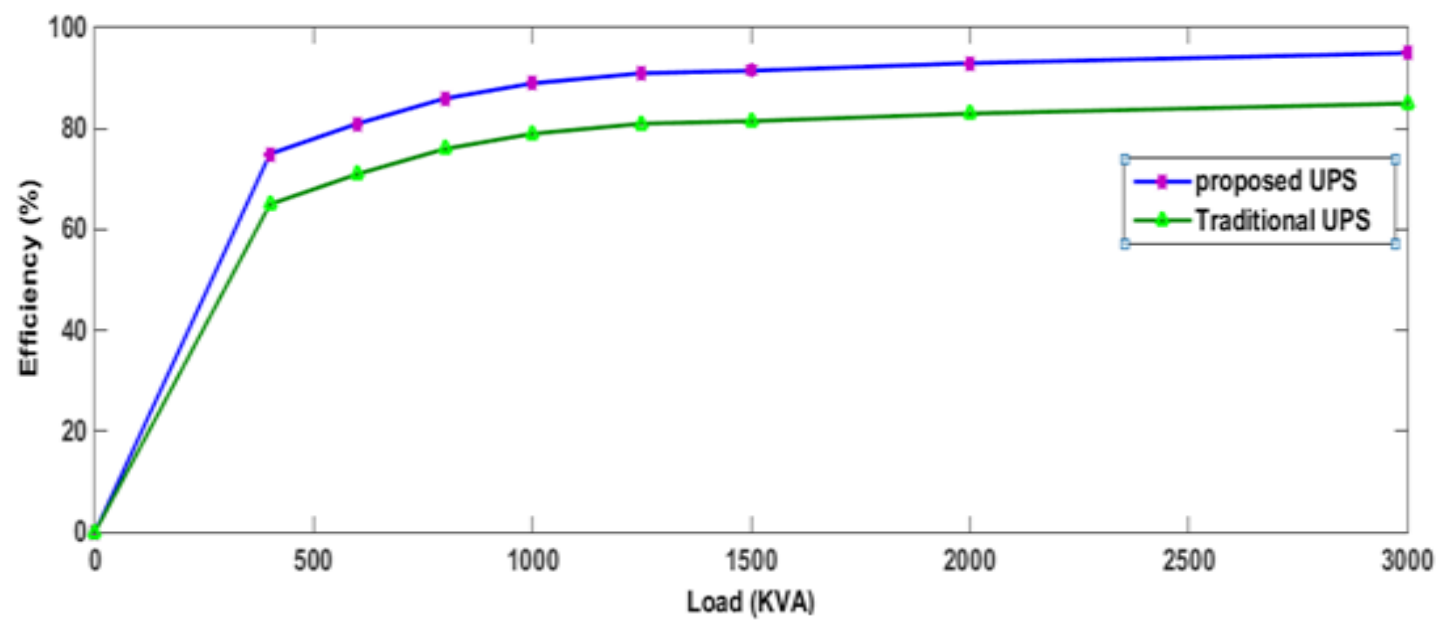

Figure 14. Proposed and traditional UPS efficiency.

\section{Hardware Implementation}

To validate the simulation result, experimental setup for NTZSI has been deliberated for 3 KVA load capacity. This setup consists of NTZSI impedance network, power circuit and feedback circuit shown in Figure 15(a). The PWM pulses for IGBT (FGA25N120AN) have been generated using ARDUINO software. The coding is embedded into the ATmega328 chip. $1 \mathrm{KHZ}$ switching frequency has been chosen. The chosen shoot though period T0 and T1 are $0.8 \times 10^{-4}$ and $4.2 \times 10^{-4}$. The simulated value of $\mathrm{d}$ and $\mathrm{M}$ are considered.

The inverter is designed for 3.7 boost factor and output $\mathrm{AC}$ voltage value of $415 \mathrm{~V}$ using Equation (35) and (37). The Equation (38) shows the expected AC line voltage value of inverter.

$$
\begin{aligned}
& B=\frac{T 1}{(n T 1+T 0) d}==\frac{4.2}{(1.5 * 4.2+0.8) 0.16}=3.7 \\
& V i=B^{*} V d c=3.7 * 154.5=571 \mathrm{~V}
\end{aligned}
$$

$V a c=M * B * V d c / 2=0.84 * 3.7 * 154.5 / 2=240.09 \mathrm{~V}$

$$
\mathrm{Vacl}=\sqrt{3} \times 240.09=415 \mathrm{~V}
$$

The Hardware implementation outcomes are shown in Figure 13 (b) and (c). During this obtained DC link voltage is $564 \mathrm{~V}$ and $\mathrm{AC}$ line voltage is $406 \mathrm{~V}$. Table 2 shows the comparative results between theoretical estimation and experimental results of NTZSI. It is observed that Experimental results are closely are closely intact with the theoretical estimation.

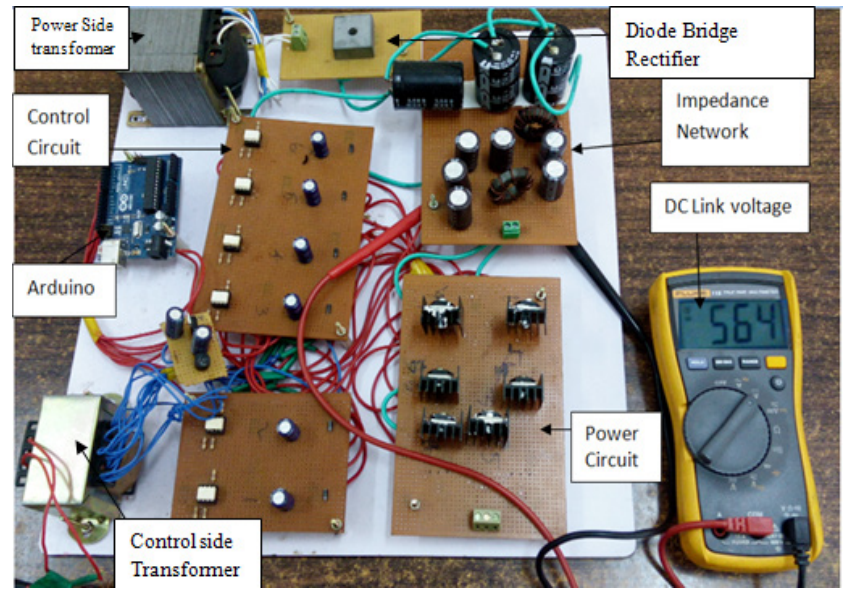

(a)

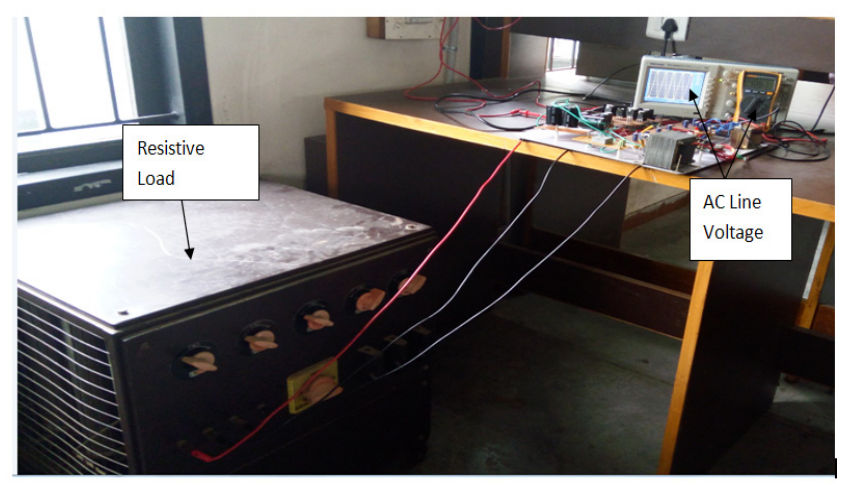

(b) 


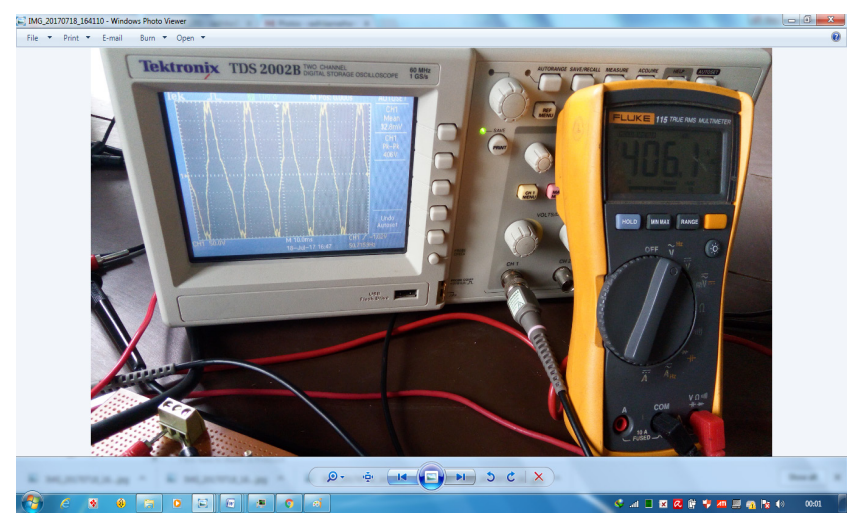

(c)

Figure 15. Hardware implementation of NTZSI showing (a) Hardware setup, (b) DC link voltage, (c) AC line voltage.

Table 2. Comparative results between theoretical estimation and experimental results

\begin{tabular}{|l|c|c|}
\hline & DC link Voltage & AC line Voltage \\
\hline Simulation Results & $571 \mathrm{~V}$ & $412 \mathrm{~V}$ \\
\hline Experimental Results & $564 \mathrm{~V}$ & $406 \mathrm{~V}$ \\
\hline
\end{tabular}

\section{Conclusion}

A brand new improved TZSI has been introduced in this paper. This inverter finds its appliance in three phase UPS for the load capacity of $3 \mathrm{KW}$. Once the load of traditional UPS raises the drop across the battery bank voltage directs to deficient $\mathrm{AC}$ voltage generation at the inverter. The ZSI based UPS resolves this trouble by regulating the shoot through time interval at the inverter side. However this inverter cannot produce enough voltage under high modulation index conditions and it desires long shoot through time interval. This raises stress across the device. In contrast to traditional ZSI UPS, the planned UPS can sustain at high modulation index condition with terribly less shoot through time interval amount and also the transformer winding turns demand is very less with this inverter. This reduces the prize and weight of the system. Here quick transient response and superior steady state performance is achieved by twin-loop control management. Simulation has been executed in MATLAB/ Simulink platform.

\section{References}

1. Zhou ZJ, Zhang X, Xu P, Shen WX. Single-phase uninterruptible power supply based on Z-source inverter.
IEEE Transactions on Industrial Electronics. 2008; 55:2997-3004. https://doi.org/10.1109/TIE.2008.924202

2. Peng FZ, Shen M, Qian Z. Maximum boost control of the Z-source inverter. IEEE Transactions on Power Electronics. 2005; 20:833-8. https://doi.org/10.1109/TPEL.2005.850927

3. Battiston A, Miliani EH, Pierfederici S, Meibody-Tabar F. A novel quasi-Z-source inverter topology with special coupled inductors for input current ripples cancellation. IEEE Transactions on Power Electronics. 2016; 31:2409-16. https://doi.org/10.1109/TPEL.2015.2429593

4. Huang Y, Shen MS, Peng FZ, Wang J. Z-source inverter for residential photovoltaic systems. IEEE Transactions on Power Electronics. 2006; 21:1776-82. https://doi. org/10.1109/TPEL.2006.882913

5. Loh PC, Tan PC, Blaabjerg F. Three level AC-DC-AC Z source converter using reduced passive component count. IEEE Transactions on Power Electronics. 2009; 24:1671-81. https://doi.org/10.1109/TPEL.2008.2011756

6. Rajaei H, Mohamadian M, Dehghan SM, Yazdian A. Single phase induction motor drive system using Z-source inverter. IET Electric Power Applications. 2010; 4:17-25. https://doi.org/10.1049/iet-epa.2008.0304

7. Zhu M, Li D, Loh PC, Blaabjerg F. Tapped-inductor Z-source inverters with novel voltage boost inversion abilities. IEEE Sustainable Energy Technologies; 2010. p. 1-6. https://doi. org/10.1109/ICSET.2010.5684446

8. Qian W, Peng FZ, Cha H. Trans-Z-source inverters. IEEE Transactions on Power Electronics. 2011; 26:3453-63. https://doi.org/10.1109/TPEL.2011.2122309

9. Huang L, Zhang M, Hang L, Yao W, Lu Z. A family of threeswitch three-state single-phase Z-source Inverters. IEEE Transactions on Power Electronics. 2013; 28:2317-29. https://doi.org/10.1109/TPEL.2012.2218132

10. Radhika A, Sivakumar L. An overview on impedance source inverter control methods, types and performance. International Journal of Applied Engineering Research. 2015; 10:33215-25.

11. Nagarajan S, Rajendran N. Comparison of fault diagnostics on Z-source and trans Z-source inverter fed induction motor drives. Indian Journal of Science and Technology. 2015; 8(32):1-9. https://doi.org/10.17485/ijst/2015/ v8i32/87868

12. Radhika A, Sivakumar L, Anamika P. Three phase uninterruptible power supply based on Tran's z source inverter. ARPN Journal of Engineering and Applied Sciences. 2016; 11(2):1365-9.

13. Ozdemir S. Z-source T-type inverter for renewable energy systems with proportional resonant controller. International Journal of Hydrogen Energy. 2016; 41(29):12591-602. https://doi.org/10.1016/j.ijhydene.2016.01.140

14. Erickson RW, Maksimovic D. Fundamentals of power electronics. Kluwar. 2nd Ed. 2001. 